\title{
THROMBOCYTOPENIC PURPURA AND CHICKENPOX
}

\author{
BY
}

\author{
R. G. WELCH \\ From St. Thomas's Hospital, London
}

(RECEIVED FOR PUBLICATION NOVEMBER 10, 1955)

Examination of the bone marrow in thrombocytopenic purpura shows two main patterns: the megakaryocytes are either deficient or else present in normal or even increased numbers. The former group results from depression of the marrow as by poisoning or mechanical displacement of the cells themselves by foreign tissue in leukaemia, infiltration with malignant cells, replacement with bone or fibrous tissue and other similar conditions. The group with a relatively normal appearance has been found to include cases due to the presence of antiplatelet bodies in the serum, to hypersplenism, to specific allergic responses to certain drugs such as 'sedormid' and 'quinidine' and others which seem to follow sufficiently closely on an infection for it to play some part in producing the condition. The following three patients developed purpura after chickenpox, although the third also had a large haemangioma, a condition itself incriminated in the past in the pathogenesis of thrombocytopenic purpura.

\section{Case Reports}

Case 1. D.W., a 6-year-old girl, 10 days after the onset of a mild attack of chickenpox developed bruises over the hips, arms and legs and in the next few nights bled a little from the gums. A week after the onset her platelet count was 106,000 per c.mm. and the Hess test strongly positive. The white cell count was normal. Four days later the platelet count had fallen to 30,000 per c.mm. and a week later to 20,000 per c.mm., though no fresh bruises had appeared in that period. The bone marrow was normal, the bleeding time $14 \frac{1}{2}$ minutes, and there was no splenomegaly. Sporadic bruising persisted for about 10 weeks, but three months after the onset of the chickenpox the platelet count was normal and the child well.

Case 2. P.R., a woman aged 26, noticed bruising on the limbs 14 days after the onset of chickenpox contracted from her nephew. Thirteen days after the onset her nose bled and two days later she started a very heavy period which persisted for more than 10 days. She had $70 \%$ haemoglobin and 3.3 million red cells per c.mm., when admitted a month after the onset of bruising, and 25,000 platelets per c.mm. The white cell count was normal. The Hess test was positive, and the bleeding time 12 minutes. The spleen was not palpable. After 10 days in which the platelet count fluctuated from 25,000 to 118,000 she was given $50 \mathrm{mg}$. A.C.T.H. sixhourly for six days, during which time the platelets rose steadily to 232,000 , only to fall subsequently. She continued to bruise for some weeks and had a further heavy period eight weeks after the previous one, but was well four months after the onset of chickenpox. Of the three patients, this one alone had taken drugs before the onset of purpura-a few compound tablets of aspirin, phenacetin and codeine which she has taken before and since without ill effects.

Case 3. L.G.C., a girl aged 19 months, who has a large haemangioma covering the left pectoral area, four or five weeks before the onset of bruising developed a crop of spots thought to be due to chickenpox which was then epidemic. Three weeks after the purpura started she was admitted to hospital covered with bruises and purpuric spots. Bleeding had occurred into the haemangioma. Investigations showed 16,000 platelets per c.mm., $75 \%$ haemoglobin, 13,000 white cells $(60 \%$ lymphocytes, $3 \%$ polymorphs, $2 \%$ monocytes, $2 \cdot 5 \%$ eosinophils, $2.5 \%$ band polymorphs, and $1 \%$ each of myelocytes, metamyelocytes and myeloblasts). The bleeding time was prolonged, the Hess test markedly positive and the spleen was not palpable. The marrow showed slight normoblastic hyperplasia and abundant megakaryocytes, but no evidence of platelet formation. Bruising ceased and the platelets rose rapidly after admission so that five weeks after the onset of the purpura she was well.

\section{Discussion}

Clinically, thrombocytopenic purpura appears in two forms, the acute and the chronic: these three cases follow the acute pattern. Hirsch and Dameshek (1951) summarized the differences. The acute type shows no special sex incidence, has an acute onset, usually as purpura and bruising in a person, often a child, with no preceding history of any unusual bleeding and no marked family history of the condition or even of easy bruising. There may well be a lymphocytosis or eosinophilia in the peripheral blood smears and similar changes in the marrow. The megakaryocytes are normal or 
increased in number, but show diminished production of platelets (Dameshek and Miller, 1946). The course is towards spontaneous and permanent recovery in a very short time-at the most four months, frequently a few weeks. The chronic type has a definite predilection for females: the patient often presents with bleeding (especially menorrhagia at puberty), but there is frequently a past history of easy bruising or excessive bleeding from minor injuries. Other members of the family may have been affected, and without treatment the condition remits and recurs over many years, although even in remission the platelet count is abnormally low.

There seems to be little doubt that many cases of thrombocytopenic purpura follow infections-particularly in childhood-and the thrombocytopenia tends to run the acute course leading usually to rapid recovery. McLean, Kreidel and Caffey (1932) reported infection in 12 of 21 children, occurring within 22 days of the onset of symptoms of purpura (two cases of measles at the 14th and 19th day of illness, one of pneumonia on the 22nd day and nine infections of the upper respiratory tract severe enough to cause fever, convulsions, cough, sore throat or nasal discharge; two had a maxillary sinusitis). Rosenthal's (1939) figures give infection in 12 ( 11 children) of 153 cases surveyed: five with glandular fever, two upper respiratory tract infections, and five after measles, chickenpox and scarlet fever. Heinild and Lindgren (1949) analysed the histories of 113 children and classified 63 as following infection (the infection as a rule within one or two weeks of onset). Twenty-one had had an upper respiratory tract infection, often streptococcal, nine had tuberculosis, seven sepsis, three Calmette vaccination, two followed wound infections, two rubella, two parotitis, one measles, one chickenpox and one diphtheria. The other 14 were labelled unknown infections. Hirsch and Dameshek (1951) had three cases following chickenpox, two after measles and rubella and two after the common cold in 18 examples of acute thrombocytopenic purpura, and noted that exacerbation in the chronic type followed infection in several. Clement and Diamond (1953) found infections in 65 of 96 children, the majority again in the upper respiratory tract, but seven had a more serious illness-rubella, chickenpox, infectious mononucleosis and pyelonephritis. Robson (1954) records that 32 of 56 cases of purpura in children were closely related to acute infection-commonly streptococcal-and 23 of these were thrombocytopenic; the other nine showed vascular fragility only. On the other hand Newton and Zuelzer (1951) were more sceptical of the part played by infection. Despite careful questioning they were unable to elicit a history of any infection in 22 of 47 cases seen and the rest had had for the most part only trivial infections-mild coryza or sore throat-although six had had measles within five weeks of the onset of symptoms. These seven papers in fact record 216 of about 500 cases of thrombocytopenic purpura in children as following infections. Excluding Robson's series where the infections are not defined, 50 of the cases $(10 \%)$ followed a specific infective illness, for the most part the acute exanthematous illnesses of childhood.

Apart from these larger series, the occurrence of thrombocytopenic purpura after measles has been reported recently by Fisher and Kraszewski (1952), after rubella by Ackroyd (1949), after infectious mononucleosis by Ogilvie and Parry (1952), and by Volpe, Sparks and Mautner (1953), and each has reviewed the previous literature. Belber, Davis and Epstein (1954) have recorded this illness after cat scratch fever, whilst Box (1933) reported several instances after scarlet fever. Cohen (1936) reported thrombocytopenic purpura in a 6-year-old boy, starting six days after the rash of chickenpox, and quotes Tancredi who wrote of two cases of purpura without thrombocytopenia in children (aged 3 and $2 \frac{1}{2}$ ) following chickenpox on the sixth and fifth days respectively. Cohen and Bansmer (1947) reported the case of an 11-year-old boy who bled into the vesicles on the third day of illness and subsequently elsewhere, and who had thrombocytopenia. They found references to 12 cases of haemorrhagic chickenpox, only four with significant haematological data, all of which recovered rapidly as did this child. Marsden and Coughlan (1952) wrote of a possible case of thrombocytopenic purpura in chickenpox starting on the third day of illness in an adult male and Hansen (1953) of a 13-year-old girl with a definite lack of platelets with symptoms starting after three days of illness. Stoesser and Lockwood (1938) watched a boy, nearly 4 years old, with chickenpox develop bruising on the fifth day of illness, then larger ecchymoses, and finally dry gangrene of both legs before recovering. He had thrombocytopenia, as did a somewhat similar but fatal case labelled purpura fulminans in an 11-year-old girl (McGovern and Dawson, 1954) who started bruising on the fourth day of illness, developed large ecchymoses on the thighs in the next two or three days and died within 30 hours of admission to hospital on the sixth day.

From all of this evidence four points emerge. First, that many infections, mild or severe, viral or bacterial, can, on occasion, be followed by thrombo- 
cytopenic purpura. Secondly, this is not a common occurrence, but whilst it is impossible to estimate the frequency, the constant pattern in all these reports suggests that the relationship is more than coincidental. Thirdly, the time between the onset of the preceding illness and the start of the purpuric symptoms can vary from a day or two to four or five weeks. Most often there is an interval of about a week between the two-in the exanthematous illness at about the time the rash is beginning to fade. Finally, there is no relationship between the severity of the original illness and the subsequent development, or indeed the severity when it does develop, of purpura.

It is accepted that in thrombocytopenic purpura there is an increased capillary fragility as well as a diminished platelet count, and whilst changes in the one usually parallel those in the other, this is not always so. Clinically it is well recognized that in recovery the bruising and bleeding may diminish before there is any demonstrable rise in the platelet count. Experimentally Bedson (1922) showed that an extensive though temporary reduction in the platelets produced no purpura in the rabbit, but that injection of an antiplatelet serum into the guinea-pig first damaged the capillary endothelium and later, when the platelets had become greatly reduced in number, red cells leaked through the capillary wall into the surrounding tissues; there were not enough platelets to make good the deficiencies in the vessel wall. Macfarlane (1941) observed by microscopy that the capillaries in thrombocytopenic purpura were distorted and failed to contract properly when punctured. Subsequently Robson and Duthie (1950) have shown that capillary fragility is reduced by A.C.T.H. and cortisone, and it is thought that much of the beneficial effects of these drugs in this condition is due to this rather than to any change in the platelet count (Faloon, Greene and Lozner, 1952).

Tocantins (1938) states that in the acute stage of infectious diseases there is in general a thrombocytopenia which gives place at the termination of infection to a moderate increase. Perlman (1934) found a rather constant tendency for the platelet count to drop below normal in a series of 50 cases of measles in the incubation period, during the height of the eruption and during the fastigium, and said the same phenomenon also occurred in the other acute exanthemata though not as consistently as in measles. Ackroyd (1949) studied the platelet count and capillary fragility in five patients developing rubella, and found a fall in the platelet count in all (though never below 130,000 per c.mm.) for a variable period up to four weeks, and an increase in capillary fragility in four. These findings, together with some damage to the skin capillaries by the toxins causing the rash, would explain the occurrence of bleeding into the rash in the acute stage of certain infectious fevers, e.g., haemorrhagic measles, but are unlikely to be the whole cause of true purpura occurring after an interval.

The presence of circulating platelet agglutinins has been shown in many cases of idiopathic thrombocytopenia (Harrington, Sprague, Minnich, Moore, Aulvin and Dubach, 1953; Stefanini, Plitman, Dameshek, Chatterjea and Mednicoff, 1953), but seldom in the acute type (Stefanini and Dameshek, 1953), nor does the plasma of the acute case produce any effect when transfused into a normal person. Volpe et al. (1953) have suggested hypersplenism as the possible cause of the purpura in their case following infectious mononucleosis. Though by no means negating this suggestion, it is remarkable how infrequently the spleen is palpable in the acute cases.

The acute onset of new symptoms after a brief quiescent period following an infective illness suggests an allergic cause: a hypersensitive response by the individual to the infecting element. The capillary changes in acute glomerulonephritis or in urticaria are evidence that such hypersensitivity can affect blood vessels. Clement and Diamond (1953) found a positive family history of allergic disorder in $30 \%$ of their 96 cases and a past personal history in $15.5 \%$. Newton and Zuelzer found that only nine of $44(21 \%)$ had had some allergic disorder previously and in 10 others there was a history of allergy in the preceding two generations. Whether the allergy affects only the capillary wall, or is responsible for inhibiting platelet production from the megakaryocytes as well, is not clear. Dameshek and Miller's (1946) description of the marrow suggests inhibition of the marrow function. Tidy (1926), however, suggested that the thrombocytopenia in purpura was secondary to the capillary damage, all the circulating platelets being used in a vain attempt to plug the leaking capillaries and the demand exceeding the supply. Lloyd (1944) thought this might be the cause of purpura in his case following mononucleosis.

Is there any common factor in all these examples of thrombocytopenic purpura following infection? It is, of course, possible that in each case there is the same organism present as secondary invader in the upper respiratory tract or skin lesions and it is in response to this that the purpura occurs. Little attention has been paid in the published series to the bacteriology, and further investigations on these lines in the future may prove illuminating. In the 
light of our present knowledge it seems that the most likely mechanism is that of an allergic response to the infection.

The third patient described above presents an additional interesting feature, and one which may be relevant to her history of purpura. Her chickenpox probably occurred four or five weeks before the onset of thrombocytopenia-the date was difficult to define-and this is longer than most of the reported cases. She had, in addition, a large haemangioma on the chest, and the combination of acute thrombocytopenia and haemangioma has been noted on several occasions. Weissman and Tagnon (1953) found five reports on infants and added two cases of their own; they suggested this was enough to establish a new syndrome. All were infants or young children, and the thrombocytopenia appeared at the time when the angioma was fully developed. Other cases are recorded by Schoo (1952) in a newborn infant, White Franklin and Williamson (1953) two cases, Good, Carnazzo and Good (1955) three cases, and Meeks, Jay and Heaton (1955), a single case-14 examples in all. Good et al. noted the presence of platelet thromboses in the vessels of the haemangioma and suggested that sequestration of platelets in the tumour accounted for the thrombocytopenia. Incidentally, the fatal case described by Silver, Aggeler and Crane (1948) had exanthema subitum a few weeks before the purpuric symptoms started so the condition might be considered as post-infective. On the other hand, in the case reported here the coexistence of haemangioma with thrombocytopenia may, as in the others reported, be purely coincidental. Apart from evidence of bruising into it, the growth showed no change during the purpuric episode, and the course of the purpura was that of a typical acute thrombocytopenia. The patient had received no radiotherapy.

\section{Summary}

Three cases of thrombocytopenia purpura following closely on chickenpox are reported. This condition follows many different types of infection on rare occasions and it is thought that the most likely cause is an allergic response to the infecting organism. The condition is self-limiting and the prognosis usually excellent.

One of the patients reported had also a large haemangioma, and the combination of this growth with thrombocytopenic purpura has been reported previously.

I am indebted to Dr. J. Forest Smith, Dr. John Anderson and Mr. Richard Battle for permission to publish details of patients admitted under their care.

\section{REFERENCES}

Ackroyd, J. F. (1949)， Quart. J.Med. (n.s.) 18, 299.

Bedson, S. P. (1922). J. Path. Bact., 25, 94.

Belber, J. P., Davis, A. E. and Epstein, E. H. (1954). Arch. intern. Med., 94, 321.

Box, C. R. (1933). Lancet, 1, 1217.

Clement, D. H. and Diamond, L. K. (1953). Amer. J. Dis. Child. 85,259

Cohen, H. J. (1936). Arch. Pediat., 53, 773.

Cohen, J. J. and Bansmer, C. (1947). New Engl. J. Med., 237, 222

Dameshek, W. and Miller, E. B. (1946). Blood, 1, 27.

Faloon, W. W., Greene, R. W. and Lozner, E. L. (1952). Amer. J. Med., 13, 12

Fisher, O. D. and Kraszewski, T. M. (1952). Archives of Disease in Childhood, 27, 144.

Franklin, A. White and Williamson, D. A. J. (1953). Ibid., 28, 490

Good, T. A., Carnazzo, S. F. and Good, R. A. (1955). Amer. J. Dis. Child., 90, 260.

Hansen, E. (1953). Ugesk. Lag., 115, 6.

Harrington, W. J., Sprague, C. C., Minnich, V., Moore, C. V., Aulvin, R. C. and Dubach, R. (1953). Ann. intern. Med., 38, 433.

Heinild, S. and Lindgren, M. L. (1949). Acta paediat. (Uppsala), Suppl. 77, p. 149

Hirsch, E. O. and Dameshek, W. (1951). Arch. intern. Med., 88, 701

Lloyd, P. C. (1944). Amer. J. med. Sci., 207, 620.

Macfarlane, R. G. (1941). Ouart. J. Med., (n.s.) 10, 1

Marsden, J. P and Coughlan, W. J. (1952). Brit. med. J., 11067.

McGovern, J. P. and Dawson, J. P. (1954). Clin. Proc. Child. Hosp. (Wash.), $10,114$.

McLean, S., Kreidel, K. and Caffey, J. (1932). J. Amer. med. Ass. 98, 387.

Meeks, E. A., Jay, J. B. and Heaton, L. D. (1955). Amer. J. Dis. Child., $90,349$.

Newton, W. A. and Zuelzer, W. W. (1951). New Engl. J. Med. $245,879$.

Ogilvie, C. M. and Parry, T. E. (1952). Brit. med. J., 2, 977.

Perlman, E. C. (1934). Arch. Pediat., 51, 596.

Robson, H. N. (1954). Int. Rec. Med., 167, 34

- and Duthie, J. J. R. (1950). Brit. med. J., 2, 971.

Rosenthal, N. (1939). J. Amer. med. Ass., 112, 101.

Schoo, A. G. (1952). Maandsch. Kindergeneesk., 20, 388.

Silver, H. K., Aggeler, P. M. and Crane, J. T. (1948). Amer. J. Dis. Child., 76, 513.

Stefanini, M. and Dameshek, W. (1953). Lancet, 2, 209

-, Plitman, G. I., Dameshek, W., Chatterjea, J. B. and Mednicoff I. B. (1953). J. Lab. clin. Med., 42,723

Stoesser, A. V. and Lockwood, W. W. (1938). J. Pediat., 12, 641.

Tidy, H. L (1926). Lancet, $2,365$.

Tocantins, L. M. (1938). Medicine (Baltimore), 17, 155.

Tocantins, L. M. (1938). Medicine (Baltimore), 17, 155 .
Volpe, R., Sparks, B. B. and Mautner, L. S. (1953). Canad. med. Ass. J., 68, 269.

Weissman, J. and Tagnon, H. J. (1953). Arch. intern. Med., 92, 523 